\title{
Assessment of Emotional Intelligence in First Year Medical Students: A Questionnaire Based Study
}

\author{
Smrithi Shetty $C^{1}$, Kavana G. Venkatappa ${ }^{1}$, Shibin Girish Parakandy ${ }^{2}$, \\ Sparshadeep E.M ${ }^{3}$, S.K. Das ${ }^{1}$ \\ I'Department of Physiology, A.J.Institute of Medical Sciences, Mangalore, Karnataka, India) \\ ${ }^{2}$ (Department of Ophthalmology, Yenepoya Medical College, Mangalore, Karnataka, India) \\ ${ }^{3}$ (Department of Pharmacology, A.J.Institute of Medical Sciences, Mangalore, Karnataka, India)
}

\begin{abstract}
Background: Emotional intelligence (EI) is increasingly made reference to in medicine and other healthcare disciplines. Assessment of EI is an important factor in determining students' adjustment and educational achievements. Lack of attention to this period of life can cause or intensify psychological disorders and lead to failure in social and educational performances.

Objectives: To assess Emotional Intelligence (EI) in first year medical students and to correlate EI with their personal and social factors.

Methods: The study included 150 first year medical students. Informed consent and ethical clearance was obtained. Self-constructed proforma was used to collect sociodemographic profile. EI was assessed using emotional quotient self-assessment checklist to which subjects responded on five-point likert scale. The data obtained was statistically analysed.

Results: $33.6 \%$ of first year medical students were poor in all domains of EI (score <20 as cut-off). Those who entered profession by choice, those who slept well and who spent more time in recreational activities and exercise were found to have good EI scores ( $p<0.05$ ). EI was significantly more in females compared to males $(p=0.02)$. Positive correlation was found among different domains of EI.

Conclusion: Good EI includes ability to understand and control emotions, to be empathetic, to be socially competent and so on and these qualities in turn improve an overall communication skill which adds on to the performance in the medical training.
\end{abstract}

Key Words: Emotional Intelligence, Empathy, First Year Medical Students, Self awareness, Self confidence.

\section{Introduction}

Emotional intelligence (EI) is one element in a broad spectrum of skills that enables an individual to create value for oneself and others. Emotional intelligence is increasingly made reference to in medicine and other healthcare disciplines where it is suggested it is important for professional mental health as well as effective practice.[1] EI helps one to build stronger relationships, succeed at work, and achieve career and personal goals. The concept of EI was introduced over a decade ago by Salovey and Mayer and is described as 'a type of social intelligence that involves the ability to monitor one's own and other's emotions, to discriminate among them, and to use this information to guide one's thinking and actions'.[2]

EI impacts many different aspects of daily life, such as the way one behaves and the way they interact with others. [3] Assessment of emotional intelligence is an important factor in determining students' adjustment and educational achievements. Attending college is a life-changing experience. It includes meeting new people and doing something novel. The first year in college, academically speaking, presents wonderful opportunities to know different academic disciplines. But since college is very different from high school, college freshmen may experience a lot of changes that can lead to problems. It is believed that emotional intelligence may explain differences in the quality of intrapersonal and interpersonal relationships and contribute to job performance and management effectiveness and predict success.[4]

Six important facets of Emotional intelligence are: self-awareness, self-confidence, self-control, empathy, motivation and social-competency. Self-awareness means having a deep understanding to one's emotions, strengths, weaknesses, needs and drives. Self-confidence is a positive and balanced attitude having to do with the Self dimension. It consists of a basic belief that we can do what is needed to produce the desired outcome. Self-control is dealing well with stress, controlling emotional moods or outbursts without overcontrol. Empathy means to be considerate and aware of other's feelings. Empathetic individuals are also effective in retaining talent because they are able to develop personal rapport with others. Motivation is a synonym for enthusiasm, initiative, and persistence. A positive attitude in the social dimension is motivation, one of the key facets of Emotional Intelligence and of leadership. Appropriate behaviour in the social dimension leads to Social 
Competency. To develop such social skills, we must focus on other people, rather than on what we are experiencing or want to say.[5]

Assessment of students' emotional intelligence is important because studying at the university is a critical period of life for efficient active young human resources of every society and it is usually associated with great changes in their social and human relationships. Lack of attention to this period of life can cause or intensify psychological disorders and lead to failure in social and educational performances.[6]

\section{AIMS}

To assess emotional intelligence and its relation with some personal and social factors in First year medical students of A.J.I.M.S, Mangalore.

\section{Materials And Methods}

The study was conducted with 150 medical students (89 females and 61 males) in their first year of study. Informed consent was taken from the students. Ethical approval was obtained from Institutional Ethical Clearance Committee, A.J.I.M.S, Mangalore. Students who commenced the first year of their study in the academic year 2011-12 were included. It is a cross-sectional, single interview study. Subjects included did not have any diagnosed medical or psychiatric illness as per history.

Self-constructed semi-structured proforma was used to collect sociodemographic profile (age, gender, socioeconomic factors, college ID number, address), profession-related characteristics (career by choice, accommodation facilities), life style factors (sleep, recreational activities, exercise) and interpersonal relationships (family support, friends). Then EI was assessed using Emotional Quotient Self-Assessment Checklist devised by Sterrett.[7]

Emotional Quotient Self-Assessment Checklist: It consists of 30 statements, five each for the areas for self-awareness, self-confidence, self-control, empathy, motivation and social-competency.

Each question was designed based on a 5-point Likert scale scoring from 1 to 5 (virtually never $=1$ to virtually always $=5$ ). The total score was the sum of all 6 domain scores. The minimum and maximum scores for each domain were 5 and 25 respectively and a cut -off value for good EI is 20 in each domain, the score below which needs improvement in the respective domain. The maximum and minimum total scores were 180 and 30 respectively. This questionnaire was prevalidated and tested for reliability (Cronbach's alpha $=0.82$ ).

The questionnaire was distributed among students in their classroom and after explaining the aims and methodology of the study, they were asked to fill the questionnaire. Data was analyzed using SPSS-17. For each student, the total score of emotional intelligence and the score of each domain were calculated. To analyze data, descriptive statistics (frequency, mean scores and standard deviation) and inferential statistics (independent ttest, Pearson correlation coefficient) were used.

\section{Results And Analysis}

The mean age of students was $18.12 \pm 0.63$ years. 89 students $(59.3 \%)$ were females and $61(40.7 \%)$ were males. There was no significant difference in age between males and females. Majority of the medical students (89.3\%) were from outside Mangalore, $81 \%$ had chosen their profession by choice, and $59.3 \%$ were not satisfied with their current accommodation facilities. Most of medical students $(61.3 \%)$ were from upper class (according to modified Kuppuswamy scale).

The time spent by medical students in college ranged from 6-8hours in a day. $76 \%$ had good sleep of 68 hours per day. More than $80 \%$ got less than 2 hours in a day for recreational activities and exercise. $84.3 \%$ of subjects perceived good interpersonal relationship with their peers of which majority were females. $79 \%$ had regular contact with their families. $24 \%$ had some or the other major problems at home like ill patients, financial issues, interpersonal problems etc.

\subsection{Subjects with Emotional Intelligence score below 20 as follows}

TABLE 1

\begin{tabular}{|l|c|}
\hline $\begin{array}{l}\text { Emotional Intelligence } \\
\text { components }\end{array}$ & Percentage of subjects (\%) \\
\hline Self-awareness & 29.2 \\
\hline Empathy & 30.1 \\
\hline Self-confidence & 35.3 \\
\hline Motivation & 32.3 \\
\hline Self-control & 36 \\
\hline Self-competency & 38.7 \\
\hline
\end{tabular}

$33.6 \%$ of first year medical students were poor in all domains of EI (score <20 as cutoff) [Table 1]. 


\section{2: Subjects with EI score below 15 as follows}

TABLE 2

\begin{tabular}{|l|c|}
\hline $\begin{array}{c}\text { Emotional Intelligence } \\
\text { components }\end{array}$ & Percentage of subjects (\%) \\
\hline Self-awareness & 6.7 \\
\hline Empathy & 6 \\
\hline Self-confidence & 15.3 \\
\hline Motivation & 21.3 \\
\hline Self-control & 18 \\
\hline Self-competency & 20.7 \\
\hline
\end{tabular}

Out of 150 subjects, nearly $15 \%$ of medical students had scores < 15 , implying a need to improve EI in these students [Table 2].

\section{3: Mean \pm Standard deviation of domain scores of emotional intelligence.}

TABLE 3

\begin{tabular}{|l|l|l|}
\hline Emotional Intelligence & Males & Females \\
\hline Self-awareness & $18.89 \pm 0.07$ & $19.31 \pm 1.44$ \\
\hline Empathy & $15.02 \pm 1.29$ & $16.01 \pm 2.32$ \\
\hline Self-confidence & $17.24 \pm 1.36$ & $18 \pm 1.59$ \\
\hline Motivation & $16.68 \pm 1.46$ & $17.02 \pm 1.26$ \\
\hline Self-control & $16.85 \pm 2.74$ & $17.03 \pm 2.47$ \\
\hline Social-competency & $17.32 \pm 1.95$ & $18.4 \pm 1.01$ \\
\hline
\end{tabular}

Table 3 shows domain scores of EI where the mean scores were higher in females than males.

4.4: Mean scores of total Emotional Intelligence in males and females. $(\mathrm{N}=150$, males $=61$, females $=89)$

\begin{tabular}{|l|l|l|l|l|l|l|}
\hline Variable & Gender & Mean & $\begin{array}{l}\text { Standard } \\
\text { deviation }\end{array}$ & $\begin{array}{l}\text { Standard } \\
\text { Error Mean }\end{array}$ & t-value & $\begin{array}{l}\text { Sig.(2- } \\
\text { tailed) }\end{array}$ \\
\hline Emotional & Male & 102.06 & 8.87 & 1.136 & 2.359 & $0.02 *$ \\
Intelligence & Female & 105.77 & 10.09 & 0.819 & & \\
& Total & 103.92 & 9.48 & & & \\
\hline
\end{tabular}

$* \mathrm{p}$ value $<0.05$.

Table 4 depicts differences between mean scores of males and females in their emotional intelligence and total EI was significantly more in females $(105.37 \pm 7.73)$ compared to males $(102.06 \pm 8.87)$ with $p$ value of 0.02 .

\section{5: Relation of Emotional Intelligence with personal and social factors:}

Students with some major problem at home were more aware of their own emotions and others feelings. EI scores were high in those who entered the profession by choice. Empathy was high in students who were in regular contact with their family $(\mathrm{p}<0.05)$ as opposed to those who were not Those who slept well and those who spent more time in recreational activities and exercise were found to have good EI scores $(p<0.05)$ than those who spent less time.

Interrelated components of EI: Positive correlation was found among different domains of EI i.e., those having high score in self awareness also scored high in self-control, motivation, competency and selfconfidence.

\section{Discussion}

The EI assessment results for the first year medical students showed that the students' total EI score was $103.92 \pm 9.48$ [Table 4]. More than $30 \%$ of the students scored $<20$ and nearly $15 \%$ of them scored below 15 [Table $1 \& 2$ ] in all the domains of EI implying a need to improve EI in these students. It is believed that emotional intelligence plays a very important role in leadership, work life and career development. Intelligent quotient (IQ) predicts only about 20 percent of career successes, which leave the remaining 80 percent to other factors such as emotional intelligence.[8] Low EI may hinder the academic success and adjustment throughout the medical training.

Females were found to have higher EI scores compared to males [Table 4]. The obtained results are in line with the findings of previous studies. $[9,10,11]$ They all found females to have higher emotional intelligence than that of males. The reason for the present findings might be due to the fact that emotional intelligence primarily deals with managing and expressing one's emotions as well as social skills.[10] It has been affirmed 
that women tend to be more emotionally expressive than men, that they understand emotions better and that they have a greater ability as regards certain interpersonal skills. Women for instance, recognize other people's emotions better, are more perceptive and have greater empathy. So their emotional intelligence ought to be higher than that of males. In addition, some evidence exists that certain areas of the brain dedicated to processing emotions could be larger in women than in men and that there is a difference in cerebral activity based on sex.[12]

Satisfaction with ones professional course as well as the choice of the career translated into higher EI in our study population.[13] Intrinsic dissatisfaction with the course would definitely be a deterrent in student's academic performance. Perhaps, the reason is related to the fact that emotional intelligence is one of the determining factors of people's adjustment and therefore, those who have more adjustment abilities have higher emotional intelligence.[6]

Time given to oneself for recreational activities, exercise and sleep has a positive effect on EI. Having some or the other major problems at home is reflected as more self awareness. With life experiences there is increased interpretation of human expression and thus corresponding increased response, sensitivity and empathy.[14]

Empathy was higher in subjects who were in regular contact with their families. The concept of understanding and managing emotions are first learned in the family, from parents and family environment; family being our first school for emotional learning.[15]

\section{Conclusion}

Good EI includes ability to understand and control emotions, to be empathetic, to be socially competent and so on and these qualities in turn improve an overall communication skill which adds on to the performance in the medical training.

1. Nearly $15 \%$ of medical students had scores < 15 in all domains of EI, implying urgent need to improve EI in these students.

2. Females had higher EI compared to males.

3. Good EI was found to be correlated with good sleep, good interpersonal relationship, recreational activities and exercise.

Thus this study provides an insight into individuals EI and its relationship with professional, interpersonal and life style factors in medical students.

Limitations of the present study:

1. The study was constrained in being limited to a single year's intake of students at one medical college.

2. Unequal distribution of sample- more female subjects.

\section{Acknowledgement}

The authors are thankful to the first year medical students who volunteered for the study.

\section{References}

[1] Pau AKH, Croucher R. Emotional intelligence and perceived stress in dental undergraduates. J Dental Education, 67(9), 2003,1023-1028.

[2] Birks Y, McKendree J, Watt I. Emotional intelligence and perceived stress in healthcare students: a multi-institutional, multiprofessional survey. BMC Med Educ, 9,2009,61.

[3] Gosling M. Measuring emotional intelligence of managers in Singapore and the application of emotional intelligence for individual and organisation effectiveness: An exploratory study[dissertation]. [Singapore]: Gosling International Pte Ltd, 2006.347p.

[4] Calaguas GM. Academic achievement and academic adjustment difficulties among college freshmen. International Refereed Research Journal,2(3),2011,72.

[5] Ahmad S, Bangash H A, Khan SA. Emotional intelligence and gender differences. Sarhad J Agric 25(1), 2009, 127-130.

[6] Zarrati I, Yazdi SA, Fallah PA. The relation between emotional intelligence and attachment styles. New in cognitive sciences, $8(1), 2006,,31-37$.

[7] Sterrett EA. The manager's pocket guide to emotional intelligence, $2^{\text {nd }}$ Ed. (Mumbai: Jaico Publishing House, 2004 ) $22-24$.

[8] Pool CR. Up with emotional health. Educational Leadership;54,199712-14.

[9] Katyal S, Aswathi E. Gender differences in emotional intelligence among adolescents of Chandigarh. J Hum Ecol,17(2),2005,153155.

[10] Sutarso P. Gender differences on the emotional intelligence inventory (EQI). Dissertation Abstracts International 1999.

[11] Wing E, Love GD. Elective Affinities and Uninvited Agonies: Mapping emotions with significant others Onto Health. Emotion, Social Relationships and Health Series in Affective Science. New York: Oxford University Press; 2001.

[12] Sanchez-Nunez MT, Fernandez-Berrocal P, Montanes J et al. Does emotional intelligence depend on gender? The socialisation of emotional competencies in men and women and its implications. Electronic Journal of Research in Educational Psychology,6(2),2008,455-474.

[13] Faye A, Kalra G, Swamy R et al. Study of emotional intelligence and empathy in medical postgraduates. Indian J Psychiatry, 53(2), 2011,140-144

[14] Girdharwal N, Singh AP. A study on emotional intelligence at health care industry, 2007. Available from:http://www.pharmainfo.net/reviews/study-emotional- intelligence-health-care-industry. (accessed on 2008)

[15] Goleman D. Working with Emotional Intelligence. 1st Ed. (New York: Bantam Books, 1998). 